\title{
Study of cord blood nucleated RBC's as a marker for fetal asphyxia
}

\section{Suvarna Jyothi Ganta*, Sunanda R. Kulkarni, Divya Renuka B.}

Department of Obstetrics and Gynaecology, Chinmaya Mission Hospital, Bangalore, Karnataka, India

Received: 08 December 2016

Revised: 02 January 2017

Accepted: 05 January 2017

\section{*Correspondence:}

Dr. Suvarna Jyothi Ganta,

E-mail: suvarnajyothi0705@gmail.com

Copyright: ( ) the author(s), publisher and licensee Medip Academy. This is an open-access article distributed under the terms of the Creative Commons Attribution Non-Commercial License, which permits unrestricted non-commercial use, distribution, and reproduction in any medium, provided the original work is properly cited.

\begin{abstract}
Background: Perinatal asphyxia is a serious problem globally and is a common cause of neonatal mortality and long term morbidity. Various Parameters are being used as predictors for birth asphyxia but the correlation between clinical presentation and the biochemical results has been unsatisfactory. NRBC count of the cord blood is reported in literature as a possible marker of perinatal asphyxia. In-utero hypoxic episode may induce a haemopoetic response of exaggerated erythropoiesis leading to the presence of nucleated RBC's in fetal circulation. The aim of this study was to investigate whether NRBC count of the cord blood can be a useful parameter to determine perinatal asphyxia.

Methods: This prospective case control study was conducted in Chinmaya Mission hospital, Bangalore, India between July 2015 to June 2016.we have studied the NRBC counts from the cord blood of 50 neonates with perinatal asphyxia and 50 healthy neonates, thus comparing the results.

Results: The mean NRBC /100 WBC for cases with birth asphyxia was 11.6 and that of the control group was 5.6. NRBC count was found to be significantly higher in neonates with low Apgar scores. There was correlation between the Apgar scores at $1^{\text {st }}$ and at 5 minutes, the degree of Hypoxic Ischemic Encephalopathy and the NRBC counts.

Conclusions: Therefore NRBC counts of the cord blood can be used as an effective tool to confirm perinatal asphyxia. It is a simple, quick, accurate and clinically effective test to diagnose and initiate treatment to prevent long term sequel of perinatal asphyxia.
\end{abstract}

Keywords: Cord blood, HIE, Hypoxia, Nucleated red blood cells, Perinatal asphyxia

\section{INTRODUCTION}

Perinatal asphyxia is a serious problem globally and is a common cause of neonatal mortality and long term morbidity. Data suggests that perinatal asphyxia contributes to almost $20 \%$ of neonatal deaths in India. ${ }^{1}$ A gold standard definition of birth asphyxia does not exist therefore it is appropriate to use the term perinatal asphyxia as asphyxia which may occur in utero, during the process of labor, at birth or in the post-natal period. WHO has defined perinatal asphyxia as "failure to initiate and sustain breathing at birth". A 2004 bulletin from the World Health Organization estimates that 900,001 total infants die each year from birth asphyxia, making it a leading cause of death for newborns. ${ }^{2}$ The complications of perinatal asphyxia are many like RDS, NEC, hypoglycemia, hypocalcemia, MAS etc. but the most severe being Hypoxemic ischemic encephalopathy and multiorgan failure. ${ }^{3}$

Parameters that are being routinely used as a predictor for birth asphyxia are thick meconium stained liquor, nonreassuring fetal heart patterns, low Apgar scores, fetal or cord blood PH. But the correlation between these clinical parameters and fetal acidosis has been unsatisfactory. NRBC count of the cord blood is reported in literature as a possible marker of perinatal asphyxia. Nucleated red blood cells are commonly seen in the newborns but rare 
in older children. In utero, hypoxic episode may induce a haemopoetic response in the form of exaggerated erythropoiesis leading to the release of immature red blood cells into the fetal circulation. ${ }^{4}$ Nucleated red blood cells can be a potentially useful tool in estimating the degree of intrauterine hypoxia. The severity of perinatal asphyxia i.e. HIE though rare can cause brain damage, neurological disability and future academic failure. Buonocore et al in his study concluded that increase in NRBC count at birth not only reflects a response of the infant to perinatal hypoxia but is also a reliable index of perinatal brain damage. ${ }^{5}$ A major challenge of modern perinatal medicine is to reduce long-term neurologic impairment of the neonate. Therefore, the search for additional markers of antenatal fetal hypoxemia is an important and relevant task. ${ }^{6}$ NRBC count in the fetal cord blood is a simple test and can be done even in low resource settings of developing countries like India. As the present markers are not accurate in diagnosis and assessing the severity of fetal asphyxia, this study was undertaken to find the values of NRBCs in normal and asphyxiated neonates and the correlation of NRBCs with birth asphyxia.

\section{METHODS}

This was a prospective case control study which was conducted in the department of OBG in Chinmaya mission hospital, Bangalore, from July 2015 to June 2016; informed consent was obtained from all subjects in the study. This study was approved by the scientific committee and ethics committee of Chinmaya mission hospital.

\section{Inclusion criteria}

The study group included neonates born to mothers in labor

- $\quad$ Between 38-42 weeks of gestation (term pregnancy)

- With singleton pregnancies who developed signs of fetal distress intrapartum.

They were monitored during labor for signs of fetal distress, like

- Thick meconium stained liquor,

- Fetal Heart rate <100beats/min,late decelerations, absent variability,

\section{Post-partum}

- Apgar score of 4 or less at 1 minute or 6 or less at 5 minutes.

- Respiratory rate $>60 / \mathrm{min}$, presence of rapid, noisy, or difficult breathing, cyanosis, chest retraction, or grunting, respiratory depression with hypotonic

- Need of resuscitation for more than 1 minute with positive pressure ventilation and oxygen,
- Control group included 50 non-asphyxiated neonates with term gestation, birth weight $>2500 \mathrm{gms}$, Apgar score $>7$ at 1 and 5 minutes of birth,

- Normal fetal heart patterns

- Clear amniotic fluid.

\section{Exclusion criteria}

- Twin pregnancies

- Prematurity

- Breech vaginal delivery

- Low birth weight infants of $<2.5 \mathrm{~kg}$

- Neonates born to mothers with pre-eclampsia

- Diabetes mellitus

- $\quad$ Rh-negative pregnancies.

From the 100 subjects, immediately after birth $2 \mathrm{ml}$ of cord blood from the clamped end of the cord was collected in sterile test tubes with EDTA (ethylene diamine tetra acetate), the cord blood was sent to the lab for estimation of $\mathrm{Hb} \%$, total leucocyte count, and peripheral smear with nucleated RBC count. Hemoglobin and white blood cell count was determined using automated hematologic blood cell counter (SYSMEX21). A thin Leishmann stained blood smear was made and nucleated red blood cells per 100 white blood cells were determined manually and the time taken for the test was 20-25 minutes.

Asphyxiated babies were transferred to the NICU (neonatal intensive care unit) after initial resuscitation. The HIE was staged as per Sarnat and Sarnat staging. ${ }^{7}$ Normal babies were shifted to the ward and followed up. Data processing and statistical analysis was done by using statistical program SPSS ver. 21.

\section{RESULTS}

Table 1 indicates clinical parameters of the study population: among the 100 neonates the mean birth weight was $3.083 \mathrm{Kg}$ and the mean gestational age was 38.63 weeks. The mean age of the mothers in the study was 27.47 years.

Table 1: Clinical parameters of the study population.

\begin{tabular}{|l|l|l|l|}
\hline Variables & Study & Control & P value \\
\hline Age of mother & $26.82 \pm 4.78$ & $28.12 \pm 4.15$ & 0.14 \\
\hline Birth weight & $3.04 \pm 0.212$ & $3.19 \pm 0.291$ & $<0.04$ \\
\hline Gestational age & $38.56 \pm 0.82$ & $38.58 \pm 0.86$ & 0.2 \\
\hline LSCS & 24 & 24 & \\
\hline NVD & 18 & 22 & \\
\hline Assist VD & 8 & 4 & \\
\hline MSAF & 33 & 1 & $<0.01$ \\
\hline $\begin{array}{l}\text { FHR } \\
\text { decelerations }\end{array}$ & 35 & 0 & $<0.01$ \\
\hline
\end{tabular}

Table 2 indicates distribution of neonates according to Apgar score at 1 and 5 minutes: the mean Apgar score of 
1 and 5minutes for the study and control group, the mean Apgar of the cases was 4.92 and 7.14 at 1 and 5 minutes respectively. And for the controls was found to be 6.74 and 8.80 .

Table 2: Distribution of neonates according to Apgar score at 1 and 5 minutes.

\begin{tabular}{|l|l|l|l|l|l|}
\hline A PGAR & Group & Mean & SD & t-value & p-value \\
\hline At $1 \mathrm{~min}$ & Case & 4.92 & 0.83 & -12.83 & $<0.01$ \\
\cline { 2 - 5 } & Controls & 6.74 & 0.56 & -14.99 & $<0.01$ \\
\hline \multirow{2}{*}{ At $5 \mathrm{~min}$} & Case & 7.14 & 0.61 & & \\
\cline { 2 - 5 } & Controls & 8.80 & 0.49 & & \\
\hline
\end{tabular}

Table 3: Correlation of Apgar score at 1 minute and NRBC count.

\begin{tabular}{|l|l|l|l|}
\hline APGAR at 1 & N & Mean NRBC & SD \\
\hline 4 & 19 & 15.32 & 6.15 \\
\hline 5 & 17 & 9.47 & 4.45 \\
\hline 6 & 28 & 7.68 & 3.15 \\
\hline 7 & 34 & 5.41 & 0.93 \\
\hline 8 & 2 & 5.50 & 0.71 \\
\hline Total & $\mathbf{1 0 0}$ & $\mathbf{8 . 6 2}$ & $\mathbf{5 . 0 8}$ \\
\hline
\end{tabular}

Table 3 indicates correlation of Apgar score at 1 minute and NRBC count: In this table the mean APGAR scores at $1 \mathrm{~min}$ and the NRBC count were compared. Low Apgar score at $1 \mathrm{~min}$ showed raised NRBC counts.
Table 4 indicates correlation of Apgar score at 1 minute and NRBC count: in this table AGPAR scores at 5 minutes and mean NRBC count were compared and higher Apgar scores showed low NRBC counts.

Table 4: Correlation of Apgar score at 5 minute and NRBC count.

\begin{tabular}{|l|l|l|l|}
\hline APGAR at 5 & N & Mean NRBC & \\
\hline 6 & 6 & 16.00 & 7.90 \\
\hline 7 & 33 & 11.33 & 5.59 \\
\hline 8 & 19 & 8.32 & 3.67 \\
\hline 9 & 42 & 5.57 & 0.91 \\
\hline Total & $\mathbf{1 0 0}$ & $\mathbf{8 . 6 2}$ & $\mathbf{5 . 0 8}$ \\
\hline
\end{tabular}

Table 5: Distribution of neonates according to NRBCs.

\begin{tabular}{|l|l|l|l|}
\hline NRBC & Controls & Cases & Total \\
\hline $0-10$ & 50 & 22 & 72 \\
\hline \multirow{2}{*}{$11-20$} & $100 \%$ & $44.0 \%$ & $72 \%$ \\
\hline \multirow{2}{*}{$21-30$} & 0 & 25 & 25 \\
\hline \multirow{2}{*}{ Total } & $0.00 \%$ & $50.0 \%$ & $25 \%$ \\
\hline & 0 & 3 & 3 \\
\hline p-value $<0.01$ & $0.0 \%$ & $6.0 \%$ & $3.0 \%$ \\
\hline & $\mathbf{5 0}$ & $\mathbf{5 0}$ & $\mathbf{1 0 0}$ \\
\hline
\end{tabular}

Table 5 indicates the distribution of neonates according to NRBCs: The number of NRBCs in the control group ranged from $0-10$ where $100 \%$ of babies had NRBCs between 0 to $10 / 100 \mathrm{WBC}$.In the case group, the NRBCs ranged from $0-30 / 100 \mathrm{WBCs}$ where $50 \%$ had NRBCs between 11-20/100WBCs. Mean NRBCs count in case and control group was 11.6 $\pm 5.73 / 100 \mathrm{WBCs}$ and $5.64 \pm 1.02 / 100 \mathrm{WBCs}$ respectively. This is again statistically significant as $\mathrm{p}<0.01$.

Table 6 shows distribution of Neonates according to laboratory parameters: In our study, the mean Hemoglobin concentration and NRBC was higher in asphyxiated neonates as correlated to normal neonates. $(\mathrm{p}<0.001$ and $\mathrm{p}<0.001$ respectively). Table 7 shows Distribution of NRBCs according to stages of HIE (Hypoxic induced encephalopathy): this table shows the correlation of HIE with NRBC counts. Among the 50 cases, 21 has no HIE, whereas 18 neonates had HIE stage 
1, 9 neonates had HIE stage 2 and 2 neonates had HIE stage 3. Present study revealed that the mean NRBC counts were higher in neonates with HIE (12.5-29) compared to the neonates who had no HIE (5.91).

Table 6: Distribution of Neonates according to laboratory parameters.

\begin{tabular}{|l|l|l|l|l|l|}
\hline Variables & Group & Mean & SD & t-value & p-value \\
\hline Hemoglobin & Cases & 20.324 & 2.046 & 4.86 & $<0.01$ \\
\hline & Controls & 18.160 & 2.385 & & \\
\hline NRBCs & Cases & 11.600 & 5.736 & 7.23 & $<0.01$ \\
\hline & Controls & 5.640 & 1.025 & & \\
\hline
\end{tabular}

Table 7: Distribution of NRBCs according to stages of HIE (Hypoxic induced encephalopathy).

\begin{tabular}{|l|l|l|l|l|l|}
\hline HIE & N & $\%$ & Mean NRBC & SD & \multicolumn{2}{|l|}{ Range } \\
\hline No HIE & 21 & $42 \%$ & 5.91 & 1.05 & $5-8$ \\
\hline Grade I & 18 & $36 \%$ & 12.50 & 1.58 & $10-15$ \\
\hline Grade II & 9 & $18 \%$ & 17.67 & 3.00 & $11-22$ \\
\hline Grade III & 2 & $4 \%$ & 29.00 & 1.41 & $28-30$ \\
\hline
\end{tabular}

Table 8: Comparison of severity of HIE with the mean NRBC count in recent studies, Mean NRBC count.

\begin{tabular}{|l|l|l|l|l|}
\hline HIE & Tunglag et al & Boskabadi et al & & Slyvia et al \\
\hline No HIE & 2.56 & 9.75 & 4.48 & Present study $^{16}$ \\
\hline HIE I & 9.1 & 11.94 & 11.10 & 5.91 \\
\hline HIE II & 14.64 & 21.08 & 25.95 & 12.50 \\
\hline HIE III & 23.01 & 29.18 & 40.55 & 17.67 \\
\hline P value & 0.001 & $<0.001$ & $<0.001$ & 29.02 \\
\hline
\end{tabular}

Table 8 shows comparison of severity of HIE with the mean NRBC count in recent studies, when compared with other recent studies carried out our results of NRBC counts to the degree of HIE were well comparable.

\section{DISCUSSION}

Nucleated red blood cells were first noted in 1871 to be present in the peripheral blood of neonates. ${ }^{8}$ They are primarily produced in the fetal bone marrow in response to erythropoietin and are stored in the marrow as precursors mature erythrocytes Studies have shown decreasing $\mathrm{nRBCs}$ as the gestational age increases, except that post-term infants have higher counts than term infants. ${ }^{9}$ Tissue hypoxia results in increased levels of erythropoietin, which in turn leads to stimulation of erythropoiesis and increased numbers of circulating nRBCs. Increased umbilical cord levels of erythropoietin have been found in pregnancies complicated by intrauterine growth restriction, post-datism maternal hypertension, pre-eclampsia, maternal smoking, Rh isoimmunisation, and maternal diabetes. ${ }^{10}$ Hence pregnancies with these co-morbidities were excluded from the present study.

In present study the mean NRBC/100WBC count in control and case group was and 11.6 $\pm 5.72 / 100 \mathrm{WBC}$ and
$5.6 \pm 1.0 / 100 \mathrm{WBC}$ respectively, which is comparable to the study by Tung lag et al where the mean NRBCs in asphyxiated neonates was $11.36 \pm 10.7$ when compared to $4.83 \pm 3.01$ in non-asphyxiated neonates, Gupta et al also in their study found $\mathrm{NRBC} / 100 \mathrm{WBC}$ count of $5.7 \pm 2.33212$ in control group and $10.34 \pm 3.87883$ in asphyxiated group. ${ }^{1,4,11}$ Also phelan et al observed in their study that the NRBC count was significantly higher in newborns with birth asphyxia than the control group. In present study 2 out of $50(4 \%)$ cases had HIE III, out of which one baby died. ${ }^{12}$

Also present study showed a strong relationship between NRBC counts and the degree of HIE i.e. higher value of NRBC/100 WBC count with greater severity of HIE; 12.50 in HIE I, 17.67 in HIE II and 29 in HIE III of HIE with $\mathrm{p}$ value as $<0.001$. Boskabadi et al in their study had found NRBC as follows, 11.94 in Grade I HIE, 21.08 in Grade II HIE and 29.18 in Grade III HIE cases, which is comparable with our study. ${ }^{13}$ Other studies which showed significant correlation between increasing NRBCs count with severityof HIE are Hermansen et al, Goel et al and Ghosh et al. ${ }^{9,14,15}$ They also reported that neurological impairment was directly related to the severity of asphyxia. Present study also shows significant relationship between NRBC levels and low APGAR scores. The Apgar scores and the NRBC count were 
found to be inversely proportional. Similar observations were done by colacoa et al and Mohanty et al. ${ }^{16,17}$

\section{CONCLUSION}

Present study, found a strong relationship between birth asphyxia and raised NRBC counts. NRBC count can be used as an effective tool to diagnose perinatal asphyxia. In low resource settings of developing countries like India where costly and invasive tests like scalp $\mathrm{PH}$ determination and fetal $\mathrm{ABG}$ analysis to assess fetal acidemia are not easily available. The determination of NRBC's from the cord sample in suspected cases of perinatal asphyxia can be used as a simple, easily available, rapid and inexpensive test to confirm and to initiate treatment early to prevent mortality and long term morbidity.

\section{Funding: No funding sources}

Conflict of interest: None declared

Ethical approval: The study was approved by the Institutional Ethics Committee

\section{REFERENCES}

1. National Neonatal and Perinatal Database Report. 2002-2003;1-58.

2. World Health organization. Neonatal and Perinatal Mortality; Country, Regional and Global estimates, 2004; WHO, Geneva. 2006;1-25.

3. Antonucci R, Porcella A, Pilloni MD. Perinatal asphyxia in the term newborn. Division of Neonatology and Pediatrics, "Nostra Signora di Bonaria". J Ped Neona Indivi Med. 2014;3(2):e030269.

4. Tung lag L, Gerelmaa Z. Nucleated red blood cell counts in asphyxiated newborns. Open Science J Clin Med. 2014;2(1):33-8.

5. Buonocore G, Perrone S, Gioia D, Gatti MG, Massafra C, Agosta R, et al. Nucleated red blood cell count at birth as an index of perinatal brain damage. Am J Obstet Gynecol. 1999;181:1500-5.

6. Roland Axt-Fliedner, KubilayErtan, Hans-Joachim Hendrik, Werner Schmidt, Neonatal Nucleated Red Blood Cell Counts Relationship to Abnormal Fetoplacental Circulation Detected by Doppler Studies, 2001 by the American Institute of Ultrasound in Medicine, J Ultrasound Med. 2001;20:183-90.
7. Sarnat HB, Sarnat MS. Neonatal Encephalopathy Following Fetal Distress. A Clinical and Electroencephalographic Study. Arch Neurol. 1976;33(10):696-705.

8. Hebbar S, Misha M, Rai L. Significance of Maternal and Cord Blood Nucleated Red Blood Cell Count in Pregnancies Complicated by Preeclampsia. India J Preg. 2014 (2014)

9. Hermansen MC. Nucleated red blood cells in the fetus and newborn. Arch Dis Child Fetal and Neonatal Ed. 2001;84(3)F211-5.

10. Jazayeri A, Tsibris JC, Spellacy WN. Elevated umbilical cord plasma erythropoietin levels in prolonged pregnancies. Obstet Gynecol. 1998;92(1):61-3.

11. Sikarwar S, Gupta S. The correlation of clinical perinatal asphyxia with counts of NRBC/100 WBC in cord blood.Web med Central Obstet Gynaecol. 2011;2(1):WMC001511.

12. Phelan JP, Kiekendall C, Korst LM, Martin G. Nucleated red blood cell and platelet counts in asphyxiated neonates sufficient to result in permanent neurological impairment in Maternal Fetal Neonatal Med. 2007;20:377-80.

13. Boskabadi H, Maamouri G, Sadeghain MH, Ghayour-Mobarhan M, Heidarzade M, Shakeri MT, et al. Early diagnosis of perinatal asphyxia by nucleated red blood cell count: a case-control study. Arch Iran Med. 2010;13(4):275-81.

14. Goel M, Dwivedi R, Gohiya P, Hegde D. Nucleated red blood cell in cord blood as a marker of perinatal asphyxia. J ClinNeonatol. 2013;2(4):179-82.

15. Ghosh B, Mittal S, Kumar S, Dadhwal V. Prediction of perinatal asphyxia with nucleated red blood cells in cord blood of new borns. Int J Gynaecol Obstet 2003;81(3):267-71.

16. Colacoa SM, Ahmeda M, Kshirsagara VY, Bajpaib R. Study of Nucleated Red Blood Cell Counts in Asphyxiated Newborns and the Fetal Outcome, Int J Clin Ped. 1927:1263.

17. Mohanty AK, Das L, Pradhan S, Meher B, Beriha SS. Cord Blood Nucleated RBC as a Predictor of Perinatal Asphyxia, Severity and Outcome. Ind J Clin Pra. 2014;24(10).

Cite this article as: Ganta SJ, Kulkarni SR, Renuka DB. Study of cord blood nucleated RBC's as a marker for fetal asphyxia. Int J Reprod Contracept Obstet Gynecol 2017;6:658-62. 